\title{
Efektifitas Model Pembelajaran Kooperatif Tipe TPS Terhadap Hasil Belajar IPS
}

\author{
Ni Putu Mila Cahyani1 ${ }^{*}$, Nyoman Dantes², Ni Wayan Rati ${ }^{3}$ \\ 13 Program Studi Pendidikan Guru Sekolah Dasar, Universitas Pendidikan Ganesha, Singaraja, Indonesia \\ 2Program Studi Bimbingan Konseling, Universitas Pendidikan Ganesha, Singaraja, Indonesia
}

\begin{abstract}
Abstrak
Penelitian ini bertujuan untuk mengetahui efektivitas model kooperatif tipe TPS terhadap hasil belajar IPS siswa di SD. Metode yang digunakan adalah metaanalisis. Sampel penelitian ini, berjumlah tujuh artikel yang diterbitkan dalam rentang waktu 2014-2020 pada jenjang sekolah dasar. Pendekatan yang digunakan adalah deskriptif kuantitatif, yaitu menghitung effect size dari tujuh artikel dengan mengidentifikasi mean, standar deviasi dan varians dari perhitungan pada uji t. Hasil analisis yang telah dilakukan bahwa secara keseluruhan nilai rata-rata effect size sebesar 1,378 , sehingga dikategorikan berefek besar yaitu $0,8 \leq 1,378 \leq 0,2$. Sehingga rata-rata tersebut membuktikan bahwa, pembelajaran dengan model kooperatif tipe TPS secara keseluruhan memiliki pengaruh yang besar terhadap hasil belajar IPS siswa. Berdasarkan dari tujuh artikel yang telah dihitung, penelitian yang dilakukan oleh (Asdar, 2016)yang paling besar efektifitasnya yaitu 3,516. Keefektifan model pembelajaran kooperatif tipe TPS juga berpengaruh terhadap penggunaan media gambar, audio visual atau konsep-konsep lain juga memberikan dampak yang signifikan pada pengaplikasian model kooperatif tipe TPS seperti multimedia, benda konkret, maupun kolaborasi dengan model kooperatif lainnya. Model Kooperatif Tipe TPS, Hasil Belajar
\end{abstract}

\begin{abstract}
This study aims to understand the effectiveness of the TPS type cooperative model on student's social studies learning outcomes in elementary school. The method used is meta-analysis. This research sampel consisted of seven articles published in the 2014-2019 at the elementary school level. The approach used is a

Keywords:

Meta Analysis, Effect Size, Model Cooperative Type TPS, Learning Outcomes quantitative descriptive that is calculating the effect size of seven articles by identifying the mean, standard deviation, and variance of the calculations in the test. The result of the analysis has been done that the overall average effect size is 1,378 so it is categorized as having a large effect $0,8 \leq 1,378 \leq 0,2$. So that the average proves that, learning with the TPS type cooperative model as a whole has a great influence on student learning outcomes in social studies. Based on the seven articles that have been counted, the largest effectiveness research conducted by (Asdar, 2016) is 3,516. The effectiveness of TPS type cooperative learning models also influences the use of media images, audio visual or other concepts also have a significant impact on the application of TPS type cooperative models such as multimedia, concrete objects, or collaboration with other cooperative models.
\end{abstract}

\footnotetext{
* Corresponding author. 


\section{PENDAHULUAN}

Pendidikan sangat berperan penting bagi peningkatan kualitas sumber daya manusia, agar memiliki kesiapan untuk menghadapi kemajuan yang semakin berkembang. (Musanna et al., 2017) menyatakan bahwa "pendidikan adalah daya-upaya untuk memajukan bertumbuhnya budi pekerti (kekuatan batin, karakter), pikiran (intellect) dan tubuh anak". Proses pendidikan harus memberi perhatian, perlakuan dan tuntunan yang seimbang dalam pengembangan karakter, intelek, dan jasmani anak didik. (Werimon et al., 2017)menyatakan bahwa "belajar ialah proses usaha yang dilakukan seseorang untuk memperoleh suatu perubahan tingkahlaku, sebagai hasil pengalamannya sendiri dalam interaksi dengan lingkungan". (Vendiagrys \& Junaedi, 2015) menyatakan bahwa "pendidikan merupakan salah satu komponen utama untuk membangun suatu bangsa".

Sekolah sebagai lembaga pendikan formal, tempat dimana berlangsungnya suatu proses pendidikan yang didalamnya terdapat proses pembelajaran. Pendidikan di sekolah dasar merupakan pendidikan anak yang berusia antara 7 tahun sampai dengan 13 tahun. Sekolah dasar ditempuh dalam waktu 6 tahun, sebagai pendidikan ditingkat dasar. Melalui sekolah dasar siswa akan memperoleh kemampuan dasar untuk mengembangkan potensi untuk melanjutkan pendidikan kejenjang selanjutnya. Dalam proses pembelajaran dipandang perlu menggunakan sebuah model pembelajaran yang inovatif agar mampu meningkatkan perkembangan pendidikan yang sejalan dengan perubahan budaya kehidupan. (Sulfemi \& Mayasari, 2019) "model pembelajaran merupakan suatu pola yang digunakan untuk penyusunan kurikulum, pengaturan materi dan berisi seperangkat petunjuk kepada guru dalam melaksanakan pembelajaran di kelas". Berhasil dan tidaknya suatu pendidikan sangat dipengaruhi oleh kurikulum yang ada. Menurut (ROKIM, 2016) "Kurikulum adalah seperangkat rencana dan pengaturan mengenai tujuan, isi dan bahan pelajaran serta cara yang digunakan sebagai pedoman penyelenggaraan kegiatan pembelajaran untuk mencapai tujuan pendidikan tertentu". Seiring dengan perkembangan jaman dan teknologi yang semakin pesat, pemerintah melakukan perubahan terhadap kurikulum dengan tujuan untuk meningkatkan kualitas pendidikan. Kurikulum yang berlaku saat ini di Indonesia yaitu kurikulum 2013, pada kurikulum 2013 ini menekankan pada pentingnya pembentukan karakter siswa.

Pembelajaran di sekolah dasar siswa diajarkan beberapa mata pelajaran salah satunya adalah mata pelajaran IPS. Pada kurikulum 2013 pembelajaran IPS di sekolah dasar terkandung ke dalam tema pembelajaran. IPS adalah singkatan dari Ilmu Pengetahuan Sosial, menurut (Ahmad, 2015)Ilmu Pengetahuan Sosial (IPS) adalah "ilmu untuk mengembangkan konsep pemikiran yang berdasarkan realita kondisi sosial yang ada di lingkungan siswa, sehingga dengan memberikan pendidikan IPS diharapkan dapat melahirkan warga negara yang baik dan bertanggung jawab terhadap bangsa dan negaranya". Sedangkan Kristin menyatakan bahwa "pengertian IPS adalah ilmu yang mempelajari berbagai displin ilmu yang terpadu berkaitan dengan manusia dan lingkungannya". Menurut (Rifai, 2016)bahwa "fungsi IPS sebagai pendidikan adalah membekali anak didik dengan pengetahuan sosial yang berguna, keterampilam sosial yang intelektual, dalam membina perhatian serta kepedulian sosialnya sebagai SDM Indonesia yang bertanggung jawab merealisasikan tujuan nasional". IPS bertujuan untuk mengembangkan potensi siswa agar peka terhadap masalah sosial yang terjadi dimasyarakat dan mampu bertindak secara efektif. Menurut (Surahman \& Mukminan, 2017)bahwa Mata pelajaran IPS bertujuan "mengembangkan potensi peserta didik agar peka terhadap masalah sosial yang terjadi dimasyarakat, memiliki sikap mental positif terhadap perbaikan segala ketimpangan yang terjadi, dan terampil mengatasi setiap masalah yang terjadi sehari-hari baik yang menimpa dirinya sendiri maupun yang menimpa kehidupan masyarakat". Selain itu menurut (Laila et al., 2016) bahwa "Salah satu tujuan utama pelajaran IPS di kelas adalah untuk membantu mengembangkan siswa menjadi warga masyarakat yang mempunyai pengetahuan, sikap, dan keterampilan yang memadai untuk berperan serta dalam kehidupan masyarakat". Berdasarkan dari tujuan IPS maka pembelajaran IPS di SD seharusnya dapat meningkatkan pengetahuan siswa tentang lingkungan sekitar baik lingkungan fisik maupun lingkungan sosial, mengenal lingkungan ditingkat kabupaten, provinsi, dan dunia. Maka guru dalam menyampaikan materi menggunakan model pembelajaran yang cocok dengan materi yang diberikan. Oleh karena itu untuk meningkatkan pemahaman serta menghindari pemahaman yang keliru, perlu ditegaskan bahwa penggunaan model pembelajaran sangat membantu guru dan siswa dalam proses pembelajaran dan mempermudah siswa dalam mengetahui dan memahami materi yang akan diberikan. Menurut (Astuti, 2017) "IPS yang diajarkan di SD terdiri atas dua kajian pokok, pengetahuan sosial dan sejarah mata pelajaran yang memberikan bekal kepada siswa, agar siswa dapat menjadi makhluk sosial yang baik, sehingga dalam kehidupannya dapat diterima dengan baik pula oleh lingkungan masyarakatnya".

Dewasa ini, pembelajaran masih cenderung dilakukan berpusat pada guru (teacher centered). Pembelajaran terkesan kaku, karena siswa tidak terlihat terlibat aktif dalam proses pembelajaran. Hal ini tentunya akan menimbulkan kebosanan di dalam kelas sehingga proses pembelajaran menjadi kurang 
maksimal, yang pada gilirannya akan berpengaruh secara bertahap terhadap hasil belajar IPS. Para guru belum sepenuhnya dapat melaksanakan pembelajaran secara aktif dan kreatif dalam melibatkan siswa serta masih belum menggunakan berbagai model maupun media pembelajaran yang bervariasi yang sesuai dengan karakter materi pembelajaran. Siswa masih perlu dibimbing untuk membiasakan diri dalam mencari dan membuka wawasannya sendiri. Seperti pendapat (Nurrita, 2018)menyatakan media pembelajaran "merupakan sumber belajar yang dapat membantu guru dalam memperkaya wawasan siswa, dengan berbagai jenis media pembelajaran oleh guru maka dapat menjadi bahan dalam memberikan ilmu pengetahuan kepada siswa".

Berdasarkan kondisi tersebut perlu adanya proses perbaikan dengan menggunakan model pembelajaran yang inovatif untuk meningkatkan hasil belajar siswa. Salah satu model pembelajaran yang dapat diterapkan pada pembelajaran IPS adalah model pembelajaran kooperatif tipe TPS (Think, Pair, Share). (Suprihatiningrum, 2016) menyatakan bahwa "pembelajaran kooperatif atau cooperatif learning mengacu pada metode pembelajaran yang mana siswa bekerja sama dalam kelompok kecil saling membantu dalam belajar". Sedangkan menurut Sugiyanto (Fiteriani, 2016) pembelajaran kooperatif adalah "model pembelajaran yang berfokus pada penggunaan kelompok kecil siswa untuk bekerja sama dalam memaksimalkan kondisi belajar untuk mencapai tujuan belajar". Hal senada juga disampaikan oleh (Zulfah, 2017) Model pembelajaran kooperatif merupakan suatu aktivitas pembelajaran yang dapat memberikan siswa kesempatan untuk saling berbagi pemikiran serta solusi dalam memecahkan suatu masalah. Pembelajaran kooperatif di dalam kelas para siswa diharapkan saling membantu, berdiskusi, dan beragumentasi untuk mengasah pengetahuan yang mereka kuasai dan menutup kesenjangan dalam perbedaan pemahaman masing-masing.

(R. D. Handayani \& Yanti, 2017) bahwa "model pembelajaran kooperatif tipe think pair share bisa membuat siswa untuk berfikir sendiri dan berdiskusi dengan temannya, serta dapat menumbuhkan partisipasi siswa". Sedangkan menurut (Rosita \& Leonard, 2015) Tipe Think Pair Share adalah "salah satu cara untuk menciptakan kerja sama siswa dalam kelompoknya, sertamemberi siswa waktu lebih banyak untuk berpikir, menjawab, dan saling membantu satu sama lain". Hal senada juga disampaikan menurut (Purwantari, n.d.) bahwa "model pembelajaran Think Pair Share (TPS) dapat meningkatkan kemampuan peserta didik dalam mengingat suatu informasi dan seorang peserta didik juga dapat belajar dari peserta didik lain, serta saling menyampaikan idenya untuk didiskusikan sebelum disampaikan di depan kelas". Adapun sintak model pembelajaran kooperatif tipe TPS menurut (Okta R.M, 2017)Sintaks pembelajaran dengan TPS sesuai dengan penemunya terlaksana dengan langkah-langkah: Thinking yaitu memikirkan, Pairing atau diskusi berpasangan, dan Sharing yaitu presentasi dan diskusi dengan seluruh kelas. Model pembelajaran kooperatif tipe TPS memiliki beberapa kelebihan di antaranya (Sari, 2018) "dapat memudahkan guru maupun siswa dalam mementukan kelompok, karena setiap kelompok terdiri dari dua siswa saja, selain itu siswa dapat lebih lelusa mengemukakan pendapatnya". Selain kelebihan model TPS juga memiliki manfaat, menurut (RAFI ACHMAD, 2019) antara lain adalah "memungkinkan peserta didik untuk bekerja sendiri dan bekerja sama dengan orang lain, mengoptimalkan partisipasi peserta didik, dan memberi kesempatan kepada peserta didik untuk menunjukkan partisipasi mereka kepada orang lain" . Adapun manfaat dari model pembelajaran TPS Menurut (Purba \& Andhanyy, 2018) Manfaat TPS antara lain adalah : memungkinkan siswa untuk bekerja sendiri dan bekerja sama dengan orang lain; mengoptimalkan partisipasi siswa; dan memberi kesempatan kepada siswa untuk menunjukkan partisipasi mereka kepada orang lain. Skill-skill yang umumnya dibutuhkan dalam pembelajaran ini adalah membagi informasi, bertanya, meringkas gagasan orang lain, dan merangkum (paraphrasing).

Namun, pada penelitian-penelitian yang dilakukan penggunaan model pembelajaran kooperatif tipe TPS terhadap hasil belajar IPS belum ada tindak lanjut terhadap hasil yang didapat, baik hasil yang didapat sesuai harapan maupun tidak. Padahal untuk mengetahui suatu keberhasilan penggunaan model adalah melakukan studi kepustakaan untuk mengetahui penyebab keberhasilan model yang digunakan atau sebagai pembanding terhadap penelitian yang dilakukan. Banyak penelitian-penelitian berupa jurnal dan artikel yang tersedia atau telah dipublikasikan diberbagai website resmi dan diakui oleh akademis. Begitu juga jurnal atau artikel yang berasal dari mahasiswa dari berbagai kampus yang ada di Indonesia. Namun, penelitian atau hasil penelitian tersebut tidak banyak dirangkum atau di uji kembali keefektifan hasil suatu penelitian tersebut. Keefektifan hasil suatu penelitian dapat di uji kembali dengan menggunakan metode meta-analisis untuk meneliti data-data hasil penelitian sebelumnya atau menjadi penguatan terhadap hasil penelitian sebelumnya. Salah satunya untuk mengetahui dampak model pembelajaran kooperatif tipe TPS terhadap hasil belajar IPS. Model pembelajaran kooperatif tipe TPS ini dirancang untuk mempengaruhi pola interaksi siswa, dan dapat memberi siswa lebih banyak waktu untuk berpikir, merespon, dan saling membantu satu sama lain yang dapat mendorong pembangunan 
pengetahuan secara integratif. Model pembelajaran kooperatif tipe TPS merupakan variabel yang mempengaruhi atau yang menjadi sebab perubahan dari hasil belajar IPS siswa.

Dalam bidang pendidikan, penelitian berbasis kepustakaan yang menggunakan metode metaanalisis telah dilakukan di jenjang pendidikan dan berbagai mata pelajaran. Beranjak dari latar belakang dan masalah tersebut, perlu dilakukan penelitian dengan metode meta-analisis pada jurnal nasional yang telah terakreditasi. Tujuannya untuk mengetahui besarnya pengaruh penggunaan model pembelajaran kooperatif tipe TPS untuk diterapkan secara umum pada pembelajaran. Berdasarkan uraian tersebut maka dilakukan penelitian dengan judul "Efektifitas Model Pembelajaran Kooperatif Tipe TPS Terhadap Hasil Belajar IPS Siswa SD".

\section{METODE PENELITIAN}

Jenis penelitian ini adalah penelitian kepustakaan, (T \& ABDI, 2017) menyatakan "studi kepustakaan juga dapat mempelajari beberbagai buku referensi serta hasil penelitian sebelumnya yang sejenis yang berguna untuk mendapatkan landasan teori mengenai masalah yang akan diteliti". pendekatan yang digunakan adalah pendekatan deskriptif kuantitatif. Pendekatan deskriptif kuantitatif adalah pendekatan yang digunakan untuk mendeskripsikan suatu permasalahan dan diuraikan dengan menggunakan angka-angka yang memiliki makna yang menggambarkan hasil penelitian yang dilakukan. Sedangkan metode penelitian yang digunakan yaitu meta-analisis. Meta-analisis merupakan teknik berupa mereview jurnal dengan menganalisis hasil penelitian yang ada di situs-situs resmi atau yang telah dipublikasikan secara nasional seperti google scholar, yang berkaitan dengan model pembelajaran kooperatif tipe TPS dalam pembelajaran IPS.

Subjek dalam penelitian ini, menggunakan sumber sekunder. Sumber sekunder merupakan sumber yang digunakan bukan diperoleh atau dikumpulkan langsung dari lapangan, melainkan hasil penelitian yang sudah dipublikasikan di situs-situs resmi dalam pendidikan, seperti google scholar, dan portal garuda. Sampel dalam penelitian berupa artikel atau jurnal yang telah dipublikasikan secara nasional, khususnya artikel yang telah dipublikasikan dengan kriteria sebagai berikut: dibuat atau ditulis oleh civitas akademika (dosen maupun mahasiswa), penelitian dilakukan di Indonesia, penelitian dalam rentang 2014 sampai 2019, penelitian dilakukan pada jenjang pendidikan SD, subyek penelitian berupa penggunaan model pembelajaran kooperatif tipe TPS terhadap hasil belajar IPS, pengujian hipotesisis dibatasi pada uji t. Instrumen dalam penelitian yang dilakukan adalah pedoman dokumentasi. Menurut (Thalha Alhamid dan Budur Anufia Ekonomi Islam, 2019) bahwa "pedoman dokumentasi yang memuat garis-garis besar atau kategori yang akan dicari datanya". Sehingga jurnal atau artikel yang dijadikan subjek penelitian harus memenuhi kriteria tersebut. Dari kriteria yang sudah ditentukan, terdapat tujuh artikel dari sembilan artikel yang akan diteliti yang termasuk ke dalam kriteria yang sudah ditentukan.

Teknik pengumpulan data menggunakan teknik observasi. Menurut (Hasanah, 2017) mendefinisikan "observasi sebagai aktivitas mencatat suatu gejala dengan bantuan instrumen-instrumen dan merekamnya dengan tujuan ilmiah atau tujuan lain". Observasi yang dilakukan adalah mengidentifikasi sumber-sumber sekunder seperti artikel, jurnal, atau web yang berhubungan dengan variabel dalam judul penelitian. Jurnal-jurnal yang akan dianalisis dan relevan dengan variabel penelitian disitus-situs resmi pendidikan. Hasil penelitian yang sudah dipublikasikan akan diseleksi terlebih dahulu dengan kriteria yang sudah ditentukan. Pengumpulan data yang sudah dilakukan, terdapat sembilan jurnal yang bertema pembelajaran dengan model kooperatif tipe TPS. Jurnal yang berjumlah sembilan tersebut, dianalisis baik isi dan data yang dibutuhkan untuk menghitung effect size, sehingga mengkrucut menjadi tujuh jurnal yang sesuai dengan kriteria yang sudah ditentukan. Teknik analisis penelitian ini menggunakan teknik analisis besar atau effect size. Menurut (TELA et al., 2019) effect size adalah "ukuran mengenai besarnya efek suatu variabel pada variabel lain besarnya perbedaan maupun hubungan yang bebas dari pengaruh sampel”. (R. Diani et al., 2018) "effect size juga dapat diangap sebagai ukuran mengenai tingkat keberhasilan peneliti". Terdapat dua rumus yang dapat digunakan untuk menghitung effect size yaitu rumus Gain dan rumis Cohen's. Menurut H. Diani et al, (2019) bahwa "Gain adalah selisih antara nilai postest dan posttest". Sedangkan menurut Ambarwati \& Setiawan, (2019) bahwa penelitian data Cohen's dimaksudkan untuk melihat besarnya variabel a terhadap variabel $b$. 
Menghitung effect size uji-t menggunakan rumus Cohen's (TELA et al., 2019) sebagai berikut:

$$
\begin{gathered}
d=\frac{x_{1}-x_{2}}{S_{g a b}} \\
S_{g a b}=\sqrt{\frac{\left(n_{1}-1\right) S_{1}^{2}+\left(n_{2}-1\right) S_{2}^{2}}{n_{1}+n_{2}-2}}
\end{gathered}
$$

Keterangan:

$$
\begin{aligned}
& \overline{x_{1}}=\text { rerata kelompok eksperimen } \\
& \overline{x_{2}}=\text { rerata keompok kontrol } \\
& n_{1} \quad \text { = jumlah sampel kelompok eksperimen } \\
& n_{2} \text { = jumlah sampel kelompok kontrol } \\
& S_{1}^{2}=\text { varians kelompok eksperimen } \\
& S_{2}{ }^{2}=\text { varians kelompok kontrol }
\end{aligned}
$$

Klasifikasi hasil perhitungan effect size menggunakan rumus Cohen's menurut (M. W. Handayani et al., 2018) pada tabel 0.4 sebagai berikut:

Tabel 1. Klasifikasi Effect Size

\begin{tabular}{cc}
\hline Besar d & Interpretasi \\
\hline$d \geq 0,8$ & Besar \\
$0,5 \leq d<0,8$ & Sedang \\
$d<0,5$ & Kecil \\
\hline
\end{tabular}

\section{ANALISIS DAN PEMBAHASAN}

Berdasarkan Tabel 0.1 tersebut bahwa pengelompokkan hasil perhitungan ke dalam efek besar, dan sedang mengacu pada klasifikasi effect size pada rumus Cohen bahwa secara keseluruhan terdapat lima jurnal yang dikateorikan besar, satu jurnal yang dikategorikan sedang, dan satu jurnal yang dikatagorikan kecil. Hasil analisis yang dilakukan, bahwa secara keseluruhan rata-rata effect size model pembelajara kooperatif tipe TPS pada penelitian yang bersifat eksprimen dari tujuh jurnal yang dianalisis mencapai angka 1,378. Sehingga dikategorikan berefek besar yaitu $0,8 \leq 0,984 \leq 0,2$.oleh karena itu, ratarata tersebut membuktikan bahwa pembelajaran dengan model kooperatif tipe TPS secara keseluruhan memiliki pengaruh yang besar terhadap hasil belajar IPS siswa. Keseluruhan jurnal yang sudah dianalisis dengan rumus Cohen's dan rumus Gain, paling besar effect sizenya pada penelitian Pengaruh Pelaksanaan Model Pembelajaran Kooperatif Tipe Think Pair Share Terhadap Hasil Belajar IPS Siswa oleh (Asdar, 2016). 
Tabel 2. Data Pengelompokan Effect Size Secara Keseluruhan

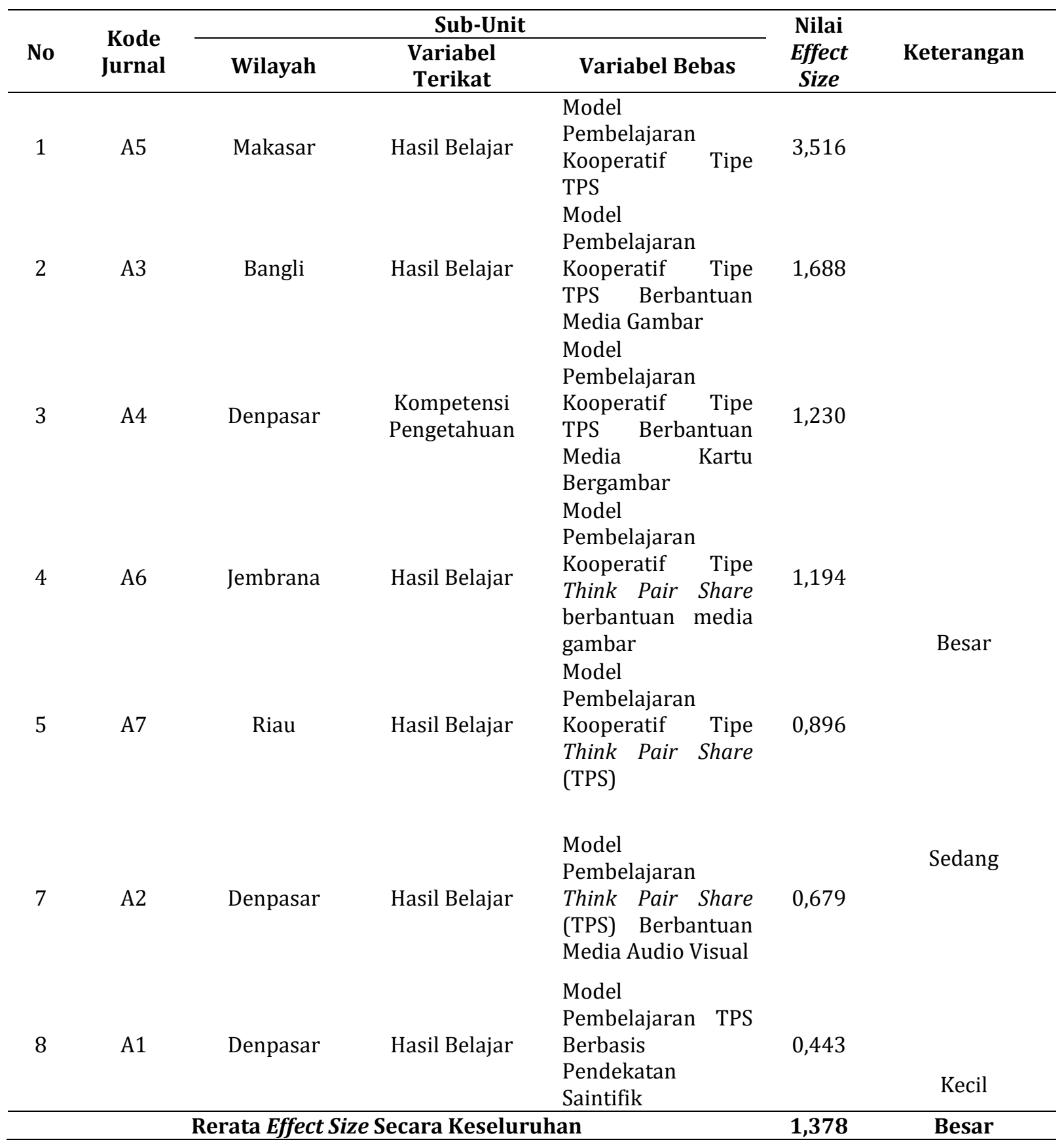

Dari ketujuh jurnal yang sudah dianalisis bahwa keefektifan model pembelajaran kooperatif tipe TPS juga berpengaruh terhadap penggunaan media gambar, audio visual atau konsep-konsep lain juga memberikan dampak yang signifikan pada pengaplikasian model kooperatif tipe TPS seperti multimedia, benda konkret, maupun kolaborasi dengan model kooperatif lainnya.

\section{KESIMPULAN}

Hasil penelitian analisis jurnal yang telah ditemukan, maka dapat disimpulkan bahwa dari tujuh hasil kajian penelitian yang relevan yang telah diseleksi berdasarkan kriteria yang ditentukan dan dihitung dengan menggunakan meta-analisis untuk mengetahui effect size. Dari analisis yang dilakukan penggunaan model pembelajaran kooperatif tipe TPS mampu meningkatkan hasil belajar IPS siswa pada kelompok eksperimen yang lebih besar dari kelompok kontrol. Hal ini membuktikan bahwa model pembelajaran kooperatif tipe TPS sangat efektif, dengan rata-rata effect size secara keseluruhan yaitu 
1,378 yang dikategorikan besar. Sehingga model pembelajaran kooperatif tipe TPS sangat cocok digunakan pada pembelajaran IPS.

Berdasarkan temuan dan hasil penelitian yang telah dilakukan dengan meta-analisis, terdapat beberapa kekurangan, sehingga ada beberapa saran yang perlu sebagai upaya perbaikan dan penelitianpenelitian yang serupa di masa datang yaitu sebagai berikut, dalam menggunakan model pembelajaran kooperatif tipe TPS pada pembelajaran IPS, guru harus menyesuaikan dengan materi dan situasi kelas. Penggunaan media atau konsep lain juga diperlukan dalam pembelajaran IPS. Sehingga indikator dan tujuan pembelajaran bisa tercapai dengan maksimal. Pada penelitian kepustakaan, diharapkan peneltian yang akan dilakukan oleh akademis menggunakan sampel penelitian yang banyak. Karena semakin banyak sampel peneltian yang digunakan, maka kualistas dari penelitian tersebut akan semakin baik. Dalam penelitian kepustakaan harus detail dan teliti. Seperti pemilihan jurnal atau artikel yang harus sesuai dengan kriteria yang telah ditentukan dan saat kegiatan menganalisis hasil kajian harus teliti agar mengurangi kesalahan dalam menginput data hasil analisis.

\section{DAFTAR PUSTAKA}

Ahmad, S. (2015). Teori Belajar \& Pembelajaran di Sekolah Dasar. Prenadamedia Group.

Ambarwati, L. H., \& Setiawan, I. (2019). Relasi Antara Kemampuan Pemahaman Matematik Siswa Smp Dengan Metode Pembelajaran Aktif Tipe Everyone Is A Teacher Here. Journal On Education, 01, 300. http://www.jonedu.org/index.php/joe/article/view/67/55

Asdar, A. F. (2016). Pengaruh Pelaksanaan Model Pembelajaran Kooperatif Tipe Think Pair Share Terhadap Hasil Belajar IPS Siswa. Journal of Educational Science and Technology, 2, 56-64. https://www.ojs.unm.ac.id/JEST/article/view/2559/1298

Astuti, D. (2017). Model Pembelajaran Think Pair Share (TPS) Untuk Meningkatan Prestasi Belajar Mata Pelajaran IPS Kelas I. Briliant: Jurnal Riset Dan Konseptual. https://doi.org/10.28926/briliant.v2i3.71

Diani, H., Irwandi, \& Fujiani, D. (2019). Pembelajaran Fisika dengan Model Brain Based Learning (BBL): Dampak pada Keterampilan Berpikir Kritis. Indonesian Journal of Sciene and Mathematcs Education, 2. https://doi.org/https://doi.org/10.24042/ijsme.v2i3.4360

Diani, R., Asyhari, A., \& Julia, O. N. (2018). Pengaruh Model Rms (Reading, Mind Mapping And Sharing) Terhadap Kemampuan Berpikir Tingkat Tinggi Siswa Pada Pokok Bahasan Impuls Dan Momentum. Jurnal Pendidikan Edutama. https://doi.org/10.30734/jpe.v5i1.128

Fiteriani, I. (2016). Model Pembelajaran Kooperatif Dan Implikasinya Pada Pemahaman Belajar Sains Di SD/MI (Studi PTK di Kelas III MIN 3 WatesLiwa Lampung Barat). Jurnal Pendidikan Dan Pembelajaran Dasar, 3, 22. https://doi.org/https://doi.org/10.24042/terampil.v3i2.1191

Handayani, M. W., Swistoro, E., \& Risdianto, E. (2018). Pengaruh Model Pembelajaran Problem Solving Fisika terhadap Kemampuan Penguasaan Konsep dan Kemampuan Pemecahan Masalah Siswa Kelas X MIPA SMAN 4 Kota Bengkulu. Jurnal Kumparan Fisika. https://doi.org/10.33369/jkf.1.3.36-44

Handayani, R. D., \& Yanti, Y. (2017). Pengaruh Model Pembelajaran Kooperatif Tipe Think Pair Share Terhadap Hasil Belajar Pkn Siswa Di Kelas IV MI Terpadu Muhammadiyah Sukarame Bandar Lampung. Jurnal Pendidikan Dan Pembelajaran Dasar.

Hasanah, H. (2017). Teknik-Teknik Observasi (Sebuah Alternatif Metode Pengumpulan Data Kualitatif Ilmu-ilmu Sosial). At-Taqaddum. https://doi.org/10.21580/at.v8i1.1163

Laila, N., Hariyono, H., \& Sumarmi, S. (2016). Meningkatkan Motivasi Belajar Siswa Pada Pembelajaran IPS Menggunakan Model Pembelajaran Kooperatif Tipe Group Investigation. Jurnal Teori Dan Praksis Pembelajaran IPS. https://doi.org/10.17977/um022v1i22016p123 
Musanna, A., Wibowo, U. B., \& Hastutiningsih, A. D. (2017). Indigenisasi Pendidikan: Rasionalitas Revitalisasi Praksis Pendidikan Ki Hadjar Dewantara. Jurnal Pendidikan Dan Kebudayaan. https://doi.org/10.24832/jpnk.v2i1.529

Nurrita, T. (2018). Pengembangan Media Pembelajaran Untuk Meningkatkan Hasil Belajar Siswa. 3, 171187.

Okta R.M, M. (2017). Implikasi Model Pembelajaran Think Pair (TPS) Berkompetisi Terhadap Hasil Belajar Kognitif Mahasiswa Dalam Mata Kuliah Geografi Lingkungan dan Sumber Daya Alam. Prosiding Seminar Nasional Biotik 2017. https://doi.org/10.1017/CB09781107415324.004

Purba, D. L., \& Andhanyy, E. (2018). Perbedaan Kemampuan Berpikir Kreatif Matematis Siswa Yang Diajar Dengan Pembelajaran Kooperatif Think Pair Share (TPS) Dan Student Teams Achievement Division (STAD) Pada Pembelajaran Matematika Di MTS Swasta Umar Bin Khattab. 7, 15. http://jurnal.uinsu.ac.id/index.php/axiom/article/view/1768/1406

Purwantari, K. (n.d.). UPAYA Meningkatkan Motivasi Dan Prestasi Belajar Matematika Dengan Model Pembelajaran Think Pair And Share (TPS). Urnal Pendidikan Matematika, 4. https://core.ac.uk/reader/230371010

Rafi Achmad. (2019). Upaya Meningkatkan Hasil Belajar Ips Materi Keanekaragaman Suku Bangsa Dan Budaya Model Pembelajaran TPS (Think Pair Dan Share) Di Kelas IV Muhammadiyah 28 Kel. Pulo Brayan Darat Ii Medan Tahun Ajaran 2018/2019 [Islam Negeri Sumatera Utara Medan]. http://repository.uinsu.ac.id/6900/1/SKRIPSI.pdf

Rifai, M. (2016). Meningkatkan Prestasi Belajar Siswa Dengan Pembelajaran Stad Pada Pembelajaran IPS Siswa Kelas IV MIN Manisrejo Kota Madiun. Premiere Educandum : Jurnal Pendidikan Dasar Dan Pembelajaran. https://doi.org/10.25273/pe.v4i02.315

Rokim, M. (2016). Survei Keterlaksanaan Kurikulum 2013 Pada Guru Pjok Di Sma Negeri Se Kabupaten Nganjuk. Jurnal Pendidikan Olahraga Dan Kesehatan.

Rosita, I., \& Leonard, L. (2015). Meningkatkan Kerja Sama Siswa Melalui Pembelajaran Kooperatif Tipe Think Pair Share. Formatif: Jurnal Ilmiah Pendidikan MIPA. https://doi.org/10.30998/formatif.v3i1.108

Sari, Y. E. (2018). PERBEDAAN Hasil Belajar Siswa Menggunakan Model Pembelajaran Think Pair Share (Tps) Dengan Model Pembelajaran Improve Materi Statistik Kelas VII SMPN 1 Sumbergempol Tulungagung [Institut Agama Islam Negeri Tulungagung]. http://repo.iaintulungagung.ac.id/9620/

Sulfemi, W. B., \& Mayasari, N. (2019). Peranan Model Pembelajaran Value Clarification Technique Berbantuan Media Audio Visual Untuk Meningkatkan Hasil Belajar IPS. Jurnal Pendidikan. https://doi.org/10.33830/jp.v20i1.772.2019

Suprihatiningrum, J. (2016). Strategi Pembelajaran: Teori dan Aplikasi. AR-RUZZ MEDIA.

Surahman, E., \& Mukminan, M. (2017). Peran guru IPS sebagai pendidik dan pengajar dalam meningkatkan sikap sosial dan tanggung jawab sosial siswa SMP. Harmoni Sosial: Jurnal Pendidikan IPS. https://doi.org/10.21831/hsjpi.v4i1.8660

T, M., \& ABDI. (2017). Studi Kepustakaan Mengenai Landasan Teori Dan Praktik Konseling Expressive Writing. Jurnal Bk Unesa. 
Tela, T., Yulian, V. N., \& Budianingsih, Y. (2019). Pengaruh Model Pembelajaran Kooperatif Tipe Think Pair Share (Tps) Terhadap Peningkatan Kemampuan Pemecahan Masalah Matematis Siswa. Biormatika: Jurnal Ilmiah Fakultas Keguruan Dan Ilmu Pendidikan. https://doi.org/10.35569/biormatika.v5i01.464

Thalha Alhamid dan Budur Anufia Ekonomi Islam. (2019). Instrumen Pengumpulan Data. Sekolah Tinggi Agama Islam Negeri (STAIN).

Vendiagrys, L., \& Junaedi, I. (2015). Unnes Journal of Mathematics Education Research Setipe Timss Berdasarkan Gaya Kognitif Siswa Pada Pembelajaran Model Problem Based Learning Abstrak. Unnes Journal of Mathematics Education Research.

Werimon, S., Damopolii, I., \& Nunaki, J. H. (2017). Pengaruh Model Pembelajaran STAD Dipadu Media Pembelajaran Komik Materi Sistem Pencernaan Manusia Terhadap Hasil Belajar Siswa. Jurnal Eksakta Pendidikan (JEP). https://doi.org/10.24036/jep.v1i2.52

Zulfah, Z. (2017). Pengaruh Penerapan Model Pembelajaran Kooperatif Tipe Think Pair Share Dengan Pendekatan Heuristik Terhadap Kemampuan Pemecahan Masalah Matematis Siswa Mts Negeri Naumbai Kecamatan Kampar. Jurnal Cendekia: Jurnal Pendidikan Matematika. https://doi.org/10.31004/cendekia.v1i2.23 